\title{
Katarakt Cerrahisi Sonrası Endoftalmiyi Önlemede Ön Kamaraya Sefuroksim İle Moksifloksasin Uygulamasının Karşılaştırılması
}

\author{
Comparison Use of Interacameral Cefuroksim of Moxifloxacin for Prophylaxis of \\ Postoperative Endophthalmitis \\ Gökhan ÇELIIK ${ }^{1}$, Hüseyin SANISOĞLU ${ }^{2}$
}

1. SBÜ, Zeynep Kamil Kadın Doğum ve Çocuk Hastalıkları SUAM, İstanbul, Türkiye

2. Serbest, İstanbul, Türkiye

\section{$\ddot{O Z Z E T}$}

Amaç: Katarakt cerrahisi bitiminde ön kamaraya sefuroksim ve moksifloksasin verilen olguları ameliyat sonrası dönemde görme keskinliklerini (GK), göz içi basinç değerlerini (GB), endotel hücre sayllarını ve ön kamara hücre saylların değerlendirmek.

Gereçler ve Yöntem: Çalışma kapsamında Haydarpaşa Numune Ĕgitim ve Araștırma Hastanesi Göz Kliniği'nde Mart 2008-Mart 2009 tarihleri arasında katarakt cerrahisi gerçekleştirilen ve ameliyat sonrasında göz içerisine sefuroksim veya moksifloksasin verilen 42 hastanın 55 gözü değerlendirilmiştir. Hastaların ameliyat öncesi ve sonrasi görme keskinlikleri, göz içi basınç değerleri, endotel hücre sayıları ve ön kamara hücre sayıları kaydedilmistitr.

Bulgular: Hastaların 20'si erkek 22 'si kadındı. yaş ortalamalarl 52.18 \pm 4.25 idi. Birinci ve Íkinci grup hastaların yaş ort. sirasivla $43.34 \pm 7.19$ ve $60.1 \pm 4.72$ idi. Birinci grupta 21 hastanın 26 gözü, ikinci grupta 21 hastanın 29 gözü değerlendirildi. Her iki grupta yas, takip süresi, amelivat öncesi ve sonrası GK ve GIB değerleri, endotel hücre saylsı, ön kamara hücre miktar ve takip süresi açısından istatistiksel olarak farklılık bulunmamiştır ( $p>0.05)$.

Sonuç: Endoftalmi profilaksisi için katarakt ameliyatı sonrası ön kamaraya sefuroksim ve moksifloksasin verilen hastalar arasinda ameliyat sonrası GK, GIB, ön kamara hücre saylsl ve endoteli hücre sayıları açısından anlamlı fark gözlenmemiştir.

Anahtar Kelimeler: endoftalmi profilaksisi, katarakt cerrahisi, intrakamaral antibiyotik

\section{ABSTRACT}

Objective: To compare postoperative visual acuity (VA), intraocular pressure (IOP), endothelial cell density and anterior chamber cell numbers of patients who received either intracameral cefuroxime or moxifloxacin at the end of cataract surgery.

Material and Methods: Fifty five eyes of 42 patients who underwent cataract surgery between March 2008 and March 2009 in the Eye Clinic of Haydarpasa Numune Education and Research Hospital were included in the study. Eyes that received intracameral cefuroxime or moxifloxacin at the end of cataract surgery were evaluated. Preoperative and postoperative $V A, I O P$ values, endothelial cell density and anterior chamber cell numbers of the patients were recorded.

\section{İletișim}

Sorumlu Yazar: Dr. Gökhan ÇELIK

Adres: SBÜ Zeynep Kamil Kadın ve Çocuk Hastalıkları SUAM, Göz Hast. Polk., B. Üstünel Cd. No: 10, 34668, Üsküdar, İstanbul, Türkiye Tel: +90 (216) 391068019

E-Posta: gcelik279@hotmail.com

Makale Geliș: 06.01.2021

Makale Kabul: 20.01.2021

DOI: http://dx.doi.org/10.16948/zktipb.855520
Results: Twenty of the patients were male and 22 of them were female. Their average age was $52.18 \pm 4.25$ years. Mean age of first (cefuroxime) and second (moxifloxacin) group patients was $43.34 \pm 7.19$ and $60.1 \pm 4.72$ years respectively. While there was 26 eyes of 21 patients in the first group, 29 eyes of 21 patients were in the second group.. No statistically significant difference was found in both groups regarding age, pre- and postoperative VA and IOP values, endothelial cell density, anterior chamber cell amount and follow-up time ( $p>0.05)$.

Conclusion: There was no significant difference in postoperative VA, IOP, anterior chamber cell count and endothelial cell density between patients who received cefuroxime and moxifloxacin to the anterior chamber at end of cataract surgery for endophthalmitis prophylaxis.

Keywords: endophthalmitis prophylaxis, cataract surgery, intracameral antibiotics

\section{GíRIS}

Katarakt cerrahisi dünyada en çok yapılan ameliyatlardan birisidir (1). Postoperatif endoftalmi profilaksisinin etkinliği fonksiyonel ve anatomik olarak cerrahi başarıda büyük rol oynar. Komplikasyonlu veya komplikasyonsuz katarakt cerrahisi sonrasında gelișebilen endoftalmi, görme kaybı ve hatta gözün kaybı ile sonuçlanabilen ciddi bir göz içi enflamasyondur. Günümüzde cerrahi asepsi-antisepsi kurallarına uyulması, ameliyat bitiminde ön kamaraya uygulanan ve ameliyat sonrası topikal olarak kullanılan antibiyotikler ile endoftalmi önlenmeye çalışılmaktadır. Fakoemülsifikasyon cerrahisinde konjonktiva florasının, ön kamaraya bulaș riski $\% 2$ ile $\% 22$ arasında bildirilmektedir $(2,3)$. $\mathrm{Bu}$ nedenle katarakt ameliyatı sonrası ön kamaraya antibiyotik uygulanmasını öneren birçok çalışma mevcuttur (4-8). Ameliyat hazırlığındaki en önemli basamak povidon iyodin ile konjonktiva fornikslerinin yıkanması olarak bilinirken, ek olarak cerrahların ameliyat bitiminde ön kamaraya antibiyotik uygulama tercihleri endoftalmi görülme oranlarını düşürdügü gösterilmiştir (4). Endoftalmi sıklığg gelişen sterilizasyon teknikleri ve cerrahi yöntemler ile yıllar içerisinde gerileyerek küçük serili çalışmalarda $\% 0$ oranına kadar düşmüştür $(5,6)$.

$\mathrm{Bu}$ çalışmanın amacı katarakt ameliyatı sonunda ön kamaraya sefuroksim ile moksifloksasin uygulamasının etkinlik ve güvenilirlik açısından sonuçlarını karşılaştırmaktır.

\section{GEREÇ ve YÖNTEM}

Çalışma kapsamında Haydarpaşa Numune Eğitim ve Araştırma Hastanesi Göz Kliniği'nde 
Mart 2008-Mart 2009 tarihleri arasinda katarakt tanisı alan veya kirma kusurlarından dolayı saydam lens aspirasyonu planlanan hastalar değerlendirildi. Tüm hastaların ameliyat öncesi ve sonrası takiplerde Snellen eșeli ile en iyi düzeltilmiş görme keskinliği (EIDGK), göz içi basıncı aplanasyon tonometresi ile ölçüldü (GIB), biyomikroskopik ve fundus bulguları kaydedildi.

Hastaların ameliyat sonras1 1.gün, 1.hafta ve 1., 3. ve 6. aylarda oftalmolojik muayeneleri tekrarland. Glokom, üveit, diyabet, korneal endotelyal hastalık öyküsü ile geçirilmiş göz operasyonu öyküsü olan, ameliyat süresi uzayan veya komplikasyon gelişen hastalar çalışma dışında bırakıldı.

Hastalar iki grupta değerlendirildi. Birinci gruptaki hastalarda hiç ultrasonik güç kullanılmadan lens aspire edildi ve intraoküler lens implantasyonu yapıldı. Bu hastalarda kendi aralarında ön kamaraya verilen antibiyotiğe göre $(1 \mathrm{mg} / 0.1 \mathrm{ml}$ sefuroksim ve $500 \mu \mathrm{g} / 0.1 \mathrm{ml}$ moksifloksasin) iki alt gruba ayrıldı. Sefuroksim verilen 11 hastanın 14 gözü ile moksifloksasin verilen 10 hastanın 12 gözü çalışma kapsamında değerlendirildi. İkinci gruptaki hastalarda ameliyat süreleri boyunca ultrasonik güç en fazla 15 saniye veya daha az süre uygulandı. Bu hastalarda kendi aralarında ön kamaraya verilen antibiyotiğe göre $(1 \mathrm{mg} / 0.1 \mathrm{ml}$ sefuroksim ve $500 \mu \mathrm{g} / 0.1 \mathrm{ml}$ moksifloksasin) iki alt gruba ayrıld 1 . Sefuroksim verilen 10 hastanın 14 gözü ve moksifloksasin verilen 11 hastanın 15 gözü değerlendirildi. Tüm hastalarda ameliyat sonras1 1.gün, 1.hafta ve 1.ayda ön kamaradaki hücre yoğunluğuna yarıklı 1ş1k mikroskobu ile bakıldı. Hücre yoğunluğu Derece 0/eser miktarda:0-5 hücre, derece +1: 6-15 hücre, derece +2 : 16-25 hücre, derece $+3: 26-50$ hücre, derece $+4: 51$ ve üzeri hücre olarak sinıflandırılarak kaydedildi.

Hastaların ameliyat öncesinde ve sonras1 1.hafta, 1.ayda kornea endotel sayımı canlı speküler mikroskobu (Tomey ${ }^{\mathrm{TM}}$ Endothelium Specular Microscope, EM-2000, Erlingen, Almanya) ile yapild1.

Cerrahiden önce tüm hastalara tam midriazis sağlamak için en az 1 saat öncesinden tropikamid \%1 (Tropamid® damla, Bilim İlaç), fenilefrin HCL $\% 2.5$, (Mydfrin ${ }^{\circledR}$ damla, Alcon) ve siklopentolat \%1 (Sikloplejin®, Abdi İbrahim) 3 kez damlatıldı. Gerekli alan temizliği sağlandıktan sonra \%5'lik povidon iyodin konjonktival cebe ve göz yüzeyine 3 dakika uygulandi. Tüm ameliyatlar lokal anestezi altında fakoemülsifikasyon yöntemi ile gerçekleştirildi. Cerrahi işlemin sonunda hastaların ön kamarasina $500 \mu \mathrm{g} / 0.1 \mathrm{ml}$ 'lik moksifloksasin (Vigamox ${ }^{\circledR}, A l c o n$ ) veya $1 \mathrm{mg} / 0.1 \mathrm{ml}$ 'lik sefuroksim (Zinnat ${ }^{\circledR}$, GlaxoSmithKline) yan girişten enjekte edildi. Elde edilen veriler istatistiksel olarak analiz edildi.

İstatistiksel Analiz: Çalışmada elde edilen veriler değerlendirilirken, istatistiksel analizler için Statistical Package for Social Sciences for Windows 17.0 (SPSS 17 inc) programı kullanılarak gerçekleştirildi. Çalışma verileri değerlendirilirken tanımlayıcı istatistiksel metodların (ortalama, standart sapma), niceliksel verilerin karşılaştırılmasında, gruplar ara-

S1 ortalama karşılaştırılmasında ve normal dağılım gösteren verilerde parametrik t-test, normal dağılım göstermeyen verilerde non parametrik Mann-Whitney U test kullanıldı. Grup içi ortalama farklar için Wilcoxon non parametrik test kullanıldı. Sonuçlar $\% 95$ 'lik güven aralığında, anlamlılık $\mathrm{p}<0.05$ düzeyinde değerlendirildi.

\section{BULGULAR}

Hastaların 20'si erkek 22'si kadındı. Yas ortalamaları 52.18 \pm 4.25 idi. Birinci ve ikinci grup hastaların yaş ortalaması sırasıyla $43.34 \pm 7.19$ ve $60.1 \pm 4.72$ idi. Birinci grupta 21 hastanın 26 gözü, ikinci grupta 21 hastanın 29 gözü değerlendirildi. Her iki grupta yaş, takip süresi, ameliyat öncesi ve sonrası GK ve GİB değerleri, endotel hücre sayısı, ön kamara hücre miktarı ve takip süresi açısından istatistiksel olarak farklılık bulunmamıştır $(\mathrm{p}>0.05)$ (Tablo 1, 2). Ameliyat sonrası takiplerde hiçbir hastada endoftalmi gelişmemiştir.

Tablo 1: Birinci gruptaki hastaların görme keskinliği, göz ici basınc1, kornea endotel sayıları ve takip sürelerinin karşılaștırması.

\begin{tabular}{|c|c|c|c|}
\hline Grup 1 & SEFUROKSİM & $\begin{array}{c}\text { MOKSİ- } \\
\text { FLOKSASIN }\end{array}$ & P değeri \\
\hline Yaş & $43,07 \pm 6,25$ & $43,66 \pm 8,27$ & $\mathrm{P}=0,836>0,05^{* *}$ \\
\hline GK (preop) & $0,58 \pm 0,18$ & $0,53 \pm 0,20$ & $\mathrm{P}=0,594>0,05^{* *}$ \\
\hline GK (1.hafta) & $0,32 \pm 0,15$ & $0,30 \pm 0,13$ & $\mathrm{P}=0,799>0,05^{* *}$ \\
\hline GK (1.ay) & $0,20 \pm 0,09$ & $0,20 \pm 0,11$ & $\mathrm{P}=0,995>0,05^{* *}$ \\
\hline GİB (preop) & $14,07 \pm 2,33$ & $14,91 \pm 2,67$ & $\mathrm{P}=0,398>0,05 * *$ \\
\hline $\begin{array}{r}\text { GİB } \\
\text { (1.hafta) }\end{array}$ & $15,00 \pm 1,70$ & $15,25 \pm 1,13$ & $\mathrm{P}=0,773>0,05^{*}$ \\
\hline $\begin{array}{r}\text { GİB } \\
\text { (1.ay) }\end{array}$ & $15,35 \pm 2,27$ & $14,33 \pm 1,72$ & $\mathrm{P}=0,214>0,05^{* *}$ \\
\hline $\begin{array}{r}\text { Endotel } \\
\text { (preop) }\end{array}$ & $2665,57 \pm 106,57$ & $2659,0 \pm 126,11$ & $\mathrm{P}=0,885>0,05^{* *}$ \\
\hline $\begin{array}{l}\text { Endotel } \\
\text { (1.hafta) }\end{array}$ & $2614,21 \pm 102,11$ & $2607,0 \pm 121,30$ & $\mathrm{P}=0,871>0,05^{* *}$ \\
\hline $\begin{array}{r}\text { Endotel } \\
(1 . a y)\end{array}$ & $2604,78 \pm 110,90$ & $2605,83 \pm 121,64$ & $\mathrm{P}=0,982>0,05^{* *}$ \\
\hline $\begin{array}{r}\text { Hücre say1s1 } \\
(1 \text {.gün })\end{array}$ & $1,75 \pm 0,62$ & $1,92 \pm 0,61$ & $\mathrm{P}=0,457>0,05^{*}$ \\
\hline $\begin{array}{r}\text { Hücre say1s1 } \\
\text { (1.hafta) }\end{array}$ & $0,75 \pm 0,45$ & $0,92 \pm 0,61$ & $\mathrm{P}=0,446>0,05^{*}$ \\
\hline $\begin{array}{r}\text { Takip süresi } \\
\text { (hafta) }\end{array}$ & $18,42 \pm 1,78$ & $18,66 \pm 2,60$ & $\mathrm{P}=0,786>0,05^{* *}$ \\
\hline
\end{tabular}


Tablo 2: Grup 2' deki hastaların hastaların görme keskinliği, göz içi basıncı ve takip sürelerinin karşılaştırması.

\begin{tabular}{|c|c|c|c|}
\hline GRUP 2 & $\begin{array}{l}\text { SEFUROK- } \\
\text { SIMM }\end{array}$ & $\begin{array}{l}\text { MOKSİ- } \\
\text { LOKSASİN }\end{array}$ & \\
\hline & $\begin{array}{c}\text { ortalama } \pm \\
\text { s.sapma }\end{array}$ & $\begin{array}{c}\text { ortalama } \pm \\
\text { s.sapma }\end{array}$ & \\
\hline Yaş & $60,64 \pm 3,77$ & $59,60 \pm 5,80$ & $\mathrm{P}=0,574>0,05^{*}$ \\
\hline GK (preop) & $0,61 \pm 0,20$ & $0,68 \pm 0,20$ & $\mathrm{P}=0,289>0,05^{* *}$ \\
\hline GK (1.hafta) & $0,28 \pm 0,09$ & $0,30 \pm 0,10$ & $\mathrm{P}=0,518>0,05^{*}$ \\
\hline GK(1.ay) & $0,18 \pm 0,08$ & $0,18 \pm 0,07$ & $\mathrm{P}=0,920>0,05^{*}$ \\
\hline GİB (preop) & $14,07 \pm 2,40$ & $14,40 \pm 2,58$ & $\mathrm{P}=0,726>0,05^{*}$ \\
\hline GİB (1.hafta) & $14,42 \pm 1,45$ & $14,60 \pm 1,18$ & $\mathrm{P}=0,717>0,05^{* *}$ \\
\hline GİB (1.ay) & $14,28 \pm 1,48$ & $13,86 \pm 2,06$ & $\mathrm{P}=0,539>0,05^{*}$ \\
\hline Hücre sayısı (1.gün) & $2,28 \pm 0,46$ & $2,26 \pm 0,45$ & $\mathrm{P}=0,910>0,05 * *$ \\
\hline Hücre sayısı (1.hafta) & $1,07 \pm 0,61$ & $1,13 \pm 0,63$ & $\mathrm{P}=0,781>0,05^{* *}$ \\
\hline Takip süresi hafta & $19,07 \pm 0,41$ & $18,60 \pm 0,50$ & $\mathrm{P}=0,519>0,05^{* *}$ \\
\hline
\end{tabular}

* t-test, ** Mann-Whitney U test.

\section{TARTIŞMA}

Antibiyotikler bakteriler üzerinde bakterisidal veya bakteriosid etkiye sahiptir. Ameliyat öncesinde, sirasinda veya sonrasinda kullanılan antibiyotikler vücut florasını baskılamakta ve yabanc1 patojenleri etkisiz hale getirmektir. Ön kamaraya antibiyotik uygulamasının amacı yüksek göz içi biyoyararlanımı sağlamak ve ameliyat sonundaki ilk saatlerde olası bulaşlara karșı etkili konsantrasyonu sağlamaktır. Vankomisin rutin katarakt cerrahisi sonrası endoftalmi proflaksisi için ön kamaraya verilen ilk antibiyotiktir. Zaman içinde vankomisine gelişen direnç ve yan etkilerinin görülmesiyle sefuroksim kullanılmaya başlanmıştır. Son zamanlarda ise moksifloksasin proflaksi için daha çok tercih edilmektedir, güncelliğini korumaktadır. Yapılan geniş serili bir çalışmada Haripriya ve ark. 2.062.643 katarakt cerrahisi sonras1 endoftalmi oranlarını $\% 0.02$ ye düşürdüklerini bildirmiştir (7). Bowen ve ark. 2017 'de 17 çalışma ve yaklaşık 900.000 hastayı içeren meta analizde katarakt cerrahisi sonrası gelişen endoftalmi oranlarını intrakamaral moksifloksasin, sefuroksim, vankomisin için sirasiyla $\% 0.332, \% 0.0153, \% 0.0106$ olarak tespit etmişlerdir (8).

Vankomisin kullanımının güvenliği ile ilgili yapılan bir çalışmada katarakt ameliyatından 2 saat sonra kültürde üreme olan aköz sıvısı örnekleri oranının $\% 13$ 'ten $\% 5$ 'e düştüğünü bildirilmiştir ve bütün bakteri kültürlerinde vankomisine duyarlılık saptanmıştır. Aynı çalışmada vankomisin konsantrasyonunun \%47'sinin ön kamarada kaldığını tespit edilmiştir. Bu oran endoftalmiye sebep olan bakterileri engellemek için en az gerekli olan 0.5- $2.0 \mu \mathrm{m} /$ $\mathrm{ml}$ konsantrasyondan çok daha yüksek olmaktadır
(9). Gimbel ve ark.'ları 12,000 katarakt ameliyatında infüzyon sıvısında gentamisin kullanmış, cerrahi sonunda kapsül içine vankomisin vermiştir ve ameliyat sonrasi enfeksiyonlu endoftalmi raporlanmamıştır (10). Diğer bir retrospektif çalışmada intrakamaral vankomisin verilen 44,863 hastada endoftalmi oran1 0,0022 olarak bildirilmiştir (11). Ancak Amerikan Hastalıkları Engelleme ve Kontrol Merkezi vankomisine karşı artan direnç uyarısında bulunmuş ve katarakt ameliyatlarında vankomisin kullanılmamasını tavsiye etmiştir (12). Relhan ve ark.'ları azalmış vankomisin duyarlılığına bağlı gram pozitif vakaların neden olduğu 27 endoftalmi vakası bildirmiştir (13). İntrakamaral vankomisin kullanımı sonrası hemorajik okluziv retinal vaskülitis vakaları görülmüş ve kuvvetle muhtemel bu olayın vankomisine bağl1 olabileceği düşünülmüşsür $(14,15)$.

Vankomisine karşı gelişen direnç nedeniyle sefuroksim katarakt cerrahisi sonrası endoftalmi proflaksisi için vankomisin yerine önerilmiștir.Ön kamaraya sefuroksim verilmesiyle ilgili ESCRS tarafindan yapılmış olan randomize, kontrollü, çok merkezli çalıșmada, hastalar 4 gruba ayrılmıștır. Ameliyat hazırlığında bütün gruplara $\% 5$ povidon iodin uygulanmış ve bazı gruplara ameliyat öncesi levofloksasin damla, ameliyat sonunda ön kamaraya sefuroksim uygulamalarından biri veya her ikisi tercih edilmiştir. Bir gruba da uygulama yapılmamıştır. Bu çalışmada 16,603 hasta izlenmiş ve gruplar arasındaki fark endoftalmi riski açısından çok anlamlı olduğu için çalışma hedeflenen 35.000 hasta sayısına ulaşmadan etik nedenlerle sona erdirilmiştir. Ön kamaraya sefuroksim verilmesiyle endoftalmi oranı 5 kat ve iki antibiyotik kullanılanla, antibiyotik kullanılmayan gruplar arasında da 7 kat fark saptanmıştır (4). (Tablo 3) Montan ve ark yaptıkları çalışmada 34102 hastanın ön kamarasına $1 \mathrm{mg} / 0.1$ $\mathrm{ml}$ sefuroksim vermiş ve 20 endoftalmiye $(\% 0.065)$ rastlamıştır. Kültürde üremesi olan 13 örnekten 12 sinin sefuroksime dirençli olduğu bildirmiştir (16).

Tablo 3: ESCRS çalışması grupları ve endoftalmi sıklıkları.
\begin{tabular}{|c|c|c|c|c|c|}
\hline Gruplar & $\begin{array}{c}\% 5 \\
\text { Povidon } \\
\text { İodin }\end{array}$ & $\begin{array}{c}\text { Preop } \\
\text { Levofloksasin }\end{array}$ & $\begin{array}{c}\text { Ön Kamaraya } \\
\text { Sefuroksim }\end{array}$ & Endoftalmi & $\begin{array}{c}\text { Kültür } \\
+ \\
\%\end{array}$ \\
\hline Grup A & + & - & - & 0345 & 0247 \\
\hline Grup B & + & - & + & 0074 & 0049 \\
\hline Grup C & + & + & - & 0247 & 0173 \\
\hline Grup D & + & + & + & 0049 & 0025 \\
\hline
\end{tabular}

Montan ve ark yaptıkları çalışmada $1 \mathrm{mg}$ ön kamaraya sefuroksim verilen ve hiçbir şey verilmeyen hastalar karşılaştırıldığında korneal endotelyal hücre sayıs1 veya morfolojisi, ön kamara hücre yoğunluğu ve santral maküla kalınlığı arasında fark bulunamamıștır (17).

Hayvan ve in vitro modellerde $\% 0.5$ moksifloksasin damlasının göz dokularında güvenli olduğu saptanmıştır. İnsan olmayan primate modelinde, \%3'lük yüksek doz moksifloksasin damla uygulanmış ve kornea endotelinde herhangi bir toksik hasar gözlemlenmemiştir (18). Kornea saklama solüsyonuna $250 \mu \mathrm{g} / \mathrm{ml}$ moksifloksasin ilave edildikten sonra kornealar elektron mikroskobide incelenmiş 
ve endotel hasarı bulgularına rastlanmamıştır (19). Staphylococcus aureusun patojen olarak seçildiği endoftalmi tavşan modelinde tavșan gözlerinin ön kamaralarına ve vitre içine 50, 125, 250, $500 \mu \mathrm{g} /$ $\mathrm{ml}$ moksifloksasin uygulanmış, endoftalmi üzerinde olumlu sonuç ile birlikte toksik etki saptanmamıştır (20). Yapılan bir çalışmada ön kamaraya $250 \mu \mathrm{g}$ $10.05 \mathrm{ml}$ moksifloksasin ve kontrol grubuna dengeli tuz solüsyonu vererek iki grup arasında görme keskinliği, göz içi basınc1, endotel sayısı, kornea kalınlıkları, aköz hücre miktarlarında anlamlı fark saptamamıştır (21). Espiritu ve ark. yaptığı çalışmada 65 göze $500 \mu \mathrm{g} / 0.1 \mathrm{ml}$ moksifloksasin ameliyat sonunda verilmiştir. Ameliyat öncesi ve sonrası 1.ay ortalama endotel say1s1 fark1 70 hücre/mm2, pakimetrik değerler fark1 17,8 $\mu \mathrm{m}$ olarak saptamıs ve istatistiksel olarak anlamlı olmadığ belirtilmiştir. Ön kamara hücre yoğunluğu 1.haftada tüm hastalarda 0/eser miktarda saptanmıștır (22).

Çalışmamızdan elde edilen veriler sonucunda, cerrahi esnasında ultrasonik gücün kullanılmadığı 1 . gruptaki hastalar ile, ultrasonik gücün kullanıldığı 2. gruptaki hastalarda ameliyat bitiminde ön kamaraya sefuroksim verilen hastalar ile moksifloksasin verilen gözler karşılaştırıldığında, bu gözler arasında endotel hücre sayıları, ön kamara hücre sayıları, görme keskinlikleri ve göz içi basınçları arasında istatistiksel olarak anlamlı fark saptanmamıştır.

Çalışmamıza dahil edilen hasta sayısı az olmasına rağmen elde edilen sonuçlar literatürdeki geniş serili çalışmaların sonuçları ile uyumludur. Sonuç olarak sefuroksim ve moksifloksasin katarakt ameliyatı sonunda endoftalmi proflaksisi için güvenle kullanılabilir.

\section{KAYNAKLAR}

1. Lindstrom R. Thoughts on cataract surgery. Review of Ophthalmology. 9 March 2015.

2. Srinivasan R, Gupta A, Kaliaperumal S, Babu RK, Thimmarayan SK, Belgode HN. Efficacy of intraoperative vancomycin in irrigating solutions on aqueous contamination during phacoemulsification. Indian J Ophthalmol. 2008;56 (5):399-402.

3. Montan PG, Koranyi G, Setterquist HE, Stridh A, Philipson $B T$, Wiklund K. Endophthalmitis after cataract surgery: risk factors relating to technique and events of the operation and patient history: a retrospective case-control study. Ophthalmology. 1998;105 (12):2171-7.

4. Prophylaxis of postoperative endophthalmitis following cataract surgery: results of the ESCRS multicenter study and identification of risk factors. Journal of cataract and refractive surgery. 2007;33 (6):978-88.

5. Beselga D, Campos A, Castro M, et al. Postcataract surgery endophthalmitis after introduction of the ESCRS protocol: a 5-year study. Eur J Ophthalmol 2013;24 (4):516-9.

6. Galvis V, Tello A, Sánchez MA, Camacho PA. Cohort study of intracameral moxifloxacin in postoperative endophthalmitis prophylaxis. Ophthalmol Eye Dis 2014;6:1.

7. Haripriya A, Chang DF, Ravindran RD. Endophthalmitis reduction with intracameral moxifloxacin in eyes with and without surgical complications: Results from 2 million consecutive cataract surgeries. J Cat Ref Surg 2019;45 (9):1226-1233.
8. Bowen RC, Zhou AX, Bondalapati S, et al. Comparative analysis of the safety and efficacy of intracameral cefuroxime, moxifloxacin and vancomycin at the end of cataract surgery: a meta-analysis. Br J Ophthalmol 2018 Jan 11.pii: bjophthalmol-2017-311051.

9. Srinivasan R, Gupta A, Kaliaperumal S, Babu RK, Thimmarayan $S K$, Belgode HN. Efficacy of intraoperative vancomycin in irrigating solutions on aqueous contamination during phacoemulsification. Indian J Ophthalmol. 2008;56 (5):399-402.

10. Montan PG, Koranyi G, Setterquist HE, Stridh A, Philipson BT, Wiklund K. Endophthalmitis after cataract surgery: risk factors relating to technique and events of the operation and patient history: a retrospective case-control study. Ophthalmology. 1998;105 (12):2171-7.

11. Mendivil Soto A, Mendivil MP. The effect of topical povidone-iodine, intraocular vancomycin, or both on aqueous humor cultures at the time of cataract surgery. American journal of ophthalmology. 2001;131 (3):293300.

12. Gimbel HV, Sun R, DeBrof BM. Prophylactic Intracameral Antibiotics During Cataract Surgery: The Incidence of Endophthalmitis and Corneal Endothelial Cell Loss. European journal of Implant and Refractive Surgery. 1994;6 (5):280-5.

13. Schelonka L, SaBell M. Postcataract endophthalmitis prophylaxis using irrigation, incision hydration, and eye pressurization with vancomycin. Clinical Ophthalmology 2015;9:1337-45.

14. Staphylococcus aureus resistant to vancomycin--United States, 2002. MMWR Morbidity and mortality weekly report. 2002;51 (26):565-7.

15. Relhan N, Albini TA, Pathengay A, Kuriyan AE, Miller D, Flynn HW. Endophthalmitis caused by Gram-positive organisms with reduced vancomycin susceptibility: literature review and options for treatment. Br J Ophthalmol 2015;100 (4):446-52.

16. ASCRS-ASRS HORV Task Force members (2016) Clinical Alert: HORV Association with Intraocular Vancomycin. http:// www.ascrs.org/sites/default/files/HORV-AlertFinal.pdf. Accessed 1st OCT 2017.

17. Witkin AJ, Chang DF, Jumper JM, et al. Vancomycin-Associated Hemorrhagic Occlusive Retinal Vasculitis. Ophthalmology 2017; 124 (5):583-95.

18. Montan PG, Kornyi G, Philipson G: Postoperative endophthalmitis (POE) in relation to different surgical techniques in cataract extractions. A postoperative study. XIth. Congress Of The European Society Of Cataract And Refractive Surgeons. Abstract Book T-M111 6, Innsbruck 1993,82.

19. Montan PG, Wejde G, Setterquist H, Rylander M, Zetterström C. Prophylactic intracameral cefuroxime: evaluation of safety and kinetics in cataract surgery. $J$ Cataract Refract Surg 2002;28 (6):982-7.

20. McGee DH, Holt WF, Kastner PR, Rice RL. Safety of moxifloxacin as shown in animal and in vitro studies. Survey of ophthalmology. 2005;50 Suppl 1:S46-54.

21. Ritterband DC, Shah MK, Meskin SW, Shapiro DE, Seedor $J A$, Koplin RS, Hu DN, Shao S, Dahl P, McCormick S. Efficacy and safety of moxifloxacin as an additive in Optisol-GS a preservation medium for corneal donor tissue. Cornea 2006; 25:1084-9.

22. Kowalski RP, Romanowski EG, Mah FS, Yates KA, Gordon $Y J$. Intracameral Vigamox (moxifloxacin 0.5\%) is non-toxic and effective in preventing endophthalmitis in a rabbit model. American journal of ophthalmology. 2005;140 (3):497-504. 